\title{
Liver transcriptome analysis of Atlantic cod (Gadus morhua) exposed to PCB 153 indicates effects on cell cycle regulation and lipid metabolism
}

\author{
Fekadu Yadetie ${ }^{1,2^{*}}$, Odd André Karlsen ${ }^{1,2}$, Marta Eide ${ }^{2}$, Christer Hogstrand ${ }^{3}$ and Anders Goksøyr ${ }^{2}$
}

\begin{abstract}
Background: Polychlorinated biphenyls (PCBs) are persistent organic pollutants (POPs) with harmful effects in animals and humans. Although PCB 153 is one of the most abundant among PCBs detected in animal tissues, its mechanism of toxicity is not well understood. Only few studies have been conducted to explore genes and pathways affected by PCB 153 by using high throughput transcriptomics approaches. To obtain better insights into toxicity mechanisms, we treated juvenile Atlantic cod (Gadus morhua) with PCB 153 (0.5, 2 and 8 mg/kg body weight) for 2 weeks and performed gene expression analysis in the liver using oligonucleotide arrays.

Results: Whole-genome gene expression analysis detected about 160 differentially regulated genes. Functional enrichment, interactome, network and gene set enrichment analysis of the differentially regulated genes suggested that pathways associated with cell cycle, lipid metabolism, immune response, apoptosis and stress response were among the top significantly enriched. Particularly, genes coding for proteins in DNA replication/cell cycle pathways and enzymes of lipid biosynthesis were up-regulated suggesting increased cell proliferation and lipogenesis, respectively.

Conclusions: PCB 153 appears to activate cell proliferation and lipogenic genes in cod liver. Transcriptional up-regulation of marker genes for lipid biosynthesis resembles lipogenic effects previously reported for persistent organic pollutants (POPs) and other environmental chemicals. Our results provide new insights into mechanisms of PCB 153 induced toxicity.
\end{abstract}

\section{Background}

Polychlorinated biphenyls (PCBs) are a class of compounds composed of 209 congeners previously used as industrial chemicals, for example in electrical equipment as flame retardants, in paints, pesticides, lubricants and sealants [1]. Although PCBs were banned in the late 1970s in the Western world, they are still one of the most problematic environmental contaminants due to their extreme persistence in the environment [2]. Because of their lipophilic nature and resistance to metabolic degradation, PCBs bioaccumulate in animals and biomagnify in the food chain [1]. Consumption of fish from contaminated areas is one of the main sources of

\footnotetext{
*Correspondence: Fekadu.Yadetie@mbi.uib.no

'Department of Molecular Biology, University of Bergen, Bergen, Norway

${ }^{2}$ Department of Biology, University of Bergen, Bergen, Norway

Full list of author information is available at the end of the article
}

exposure to humans [3]. Based on chemical structure, PCBs are classified into two major groups with different modes of toxicity, i.e. the dioxin-like co-planar PCBs that bind the aryl hydrocarbon receptor (AhR) (e.g. PCB 126) and the non-coplanar PCBs such as PCB $153[1,4]$. The co-planar PCBs have toxicity mechanisms mainly mediated by AhR, with a range of toxic effects including carcinogenicity, developmental toxicity, neurotoxicity, immune suppression and endocrine disruption [1]. The non-coplanar PCBs such as PCB 153 do not bind to and activate AhR, and their mechanisms of toxicity are at present less well understood. The non-coplanar PCBs such as PCB 153 may act via the steroid and xenobiotic receptor (SXR), also known as pregnane $\mathrm{X}$ receptor (PXR), and the constitutive androstane receptor (CAR) [5,6].

PCB 153 is one of the PCB congeners often detectable in biological samples [1,4], and it is commonly used as a 
representative compound for the non-dioxin-like (noncoplanar) PCB congeners in toxicological investigations. It is among the most persistent congeners, with residence time in the environment exceeding 100 years [2]. Toxic effects of PCB 153 include possible endocrine disruption $[7,8]$, neurotoxicity [9], and liver tumor promotion [10]. Accumulating evidences suggest that PCBs and other persistent organic pollutants (POPs) may also act as metabolic disruptors contributing to growing incidence of metabolic diseases [11-17]. A recent study showed that PCB 153 exacerbated obesity in mice when administered in combination with a high-fat-diet resulting in increased visceral adiposity, hepatic steatosis, plasma adipokines, as well as up-regulation and downregulation of genes for hepatic lipid biosynthesis and degradation, respectively [18]. In mouse fibroblast 3T3L1 cells, PCB 153 and other environmental chemicals have been shown to promote adipogenesis $[16,19,20]$. Studies using zebrafish (Danio rerio) suggest that fish can be useful models in exploring effects of environmental chemicals that may act as metabolic disruptors [21-23]. To date, no studies have explored effects PCB 153 toxicity in fish liver using high throughput approaches, perhaps partly due to lack of sequenced and annotated genomes for many fish species. The Atlantic cod is a commercially important species that is also commonly used in monitoring environmental pollution and laboratory toxicological investigations $[9,24-26]$. The sequencing of its genome [27] has recently enabled us to apply genomic approaches to study toxicant effects in this organism $[25,28]$. Exposure to individual PCB congeners, such as PCB 153, and subsequent analysis using global approaches like transcriptome assays should enable a better understanding of the toxic effects and the mechanisms involved. Such mechanistic toxicogenomics studies are increasingly recognized as important components in developing models that can help in risk assessment of environmental contaminants [29-31]. Furthermore, high throughput transcriptomics approaches may facilitate identification of new biomarkers that can be applied in improved monitoring of pollution in the aquatic environment.

The aim of this study was to map the range of molecular targets of PCB 153 and gain better insights into its toxicity mechanisms in the liver of Atlantic cod, using recently developed oligonucleotide arrays [28]. A genome-wide transcriptome analysis of Atlantic cod liver was performed after exposure to PCB 153, and various bioinformatics approaches were applied to explore the major genes and pathways affected, and the possible toxicity mechanisms involved.

\section{Results and discussion}

\section{Differentially regulated genes}

Analysis of the microarray data resulted in 160 candidate genes differentially regulated in the highest dose $(8 \mathrm{mg} / \mathrm{kg}$
BW PCB 153) group, using SAM (Significance Analysis of Microarrays) at FDR (False Discovery Rate) $\leq 10 \%$ (Additional file 1:Table S1). Five genes found to be differentially regulated by qPCR (Quantitative real-time polymerase chain reaction) assay (see below) were also included in Additional file 1: Table S1. This list of 165 differentially regulated genes was used for pathway enrichment analysis in DAVID (Database for Annotation, Visualization and Integrated Discovery) and MetaCore (see below). Although no differentially regulated genes were detected for the lower 0.5 and $2 \mathrm{mg} / \mathrm{kg} \mathrm{BW}$ PCB 153 doses (at the $10 \%$ FDR cut-off), a dose-response trend is apparent in the expression of the differentially regulated genes as indicated by hierarchical clustering analysis (Figure 1). In the hierarchical clustering, the PCB 153 treated samples are well separated from the control samples, and the dose groups are co- clustered except one $(2 \mathrm{mg} / \mathrm{kg} \mathrm{BW})$ sample that was grouped with the lowest dose group. In general high individual variability was observed in the microarray data, which combined with a limited number of samples $(n=3-4)$, appear to have contributed to moderate levels of statistical significance for differential regulation. Thus, Gene Set Enrichment Analysis (GSEA), which is an independent approach for pathway enrichment analysis that uses the whole set of genes without pre-selection [32], was also performed in addition to pathway analysis using DAVID and MetaCore performed with the differentially regulated genes. In addition, selected genes in the affected pathways were assayed by qPCR on a larger sample size to confirm the microarray data (see below).

\section{qPCR assay}

To confirm the microarray results in a larger number of samples ( $n=8-10$ per group), the mRNA levels of 10 up-regulated genes selected based on their relevance in the most enriched lipid metabolism and cell cycle related pathways were analyzed by qPCR (Figure 2). Half of these genes were selected from the differentially regulated list (Additional file 1: Table S1). Another five genes (FABP7, TMM97, PPARG, SREBP1 and PCNA) that were up-regulated by microarray but not at significant levels (FDR >10) were also included in the PCR assay. A doseresponse trend was observed for all the genes and statistical analysis using one-way ANOVA showed 6 of the 10 genes were significantly up-regulated in at least one dose group of PCB 153 treated fish as determined by qPCR assays (Figures $2 \mathrm{~A}-\mathrm{J}$ ), thus confirming and strengthening the microarray results.

Validation of the microarray method by qPCR was also performed by direct comparison of fold-changes obtained by the two methods only in the subset of samples analyzed by microarrays ( $\mathrm{n}=3-4$ per group). Expression levels of 7 of the above genes and additional randomly selected 5 genes (MCM5, ADK, APOH, MTL2A and 


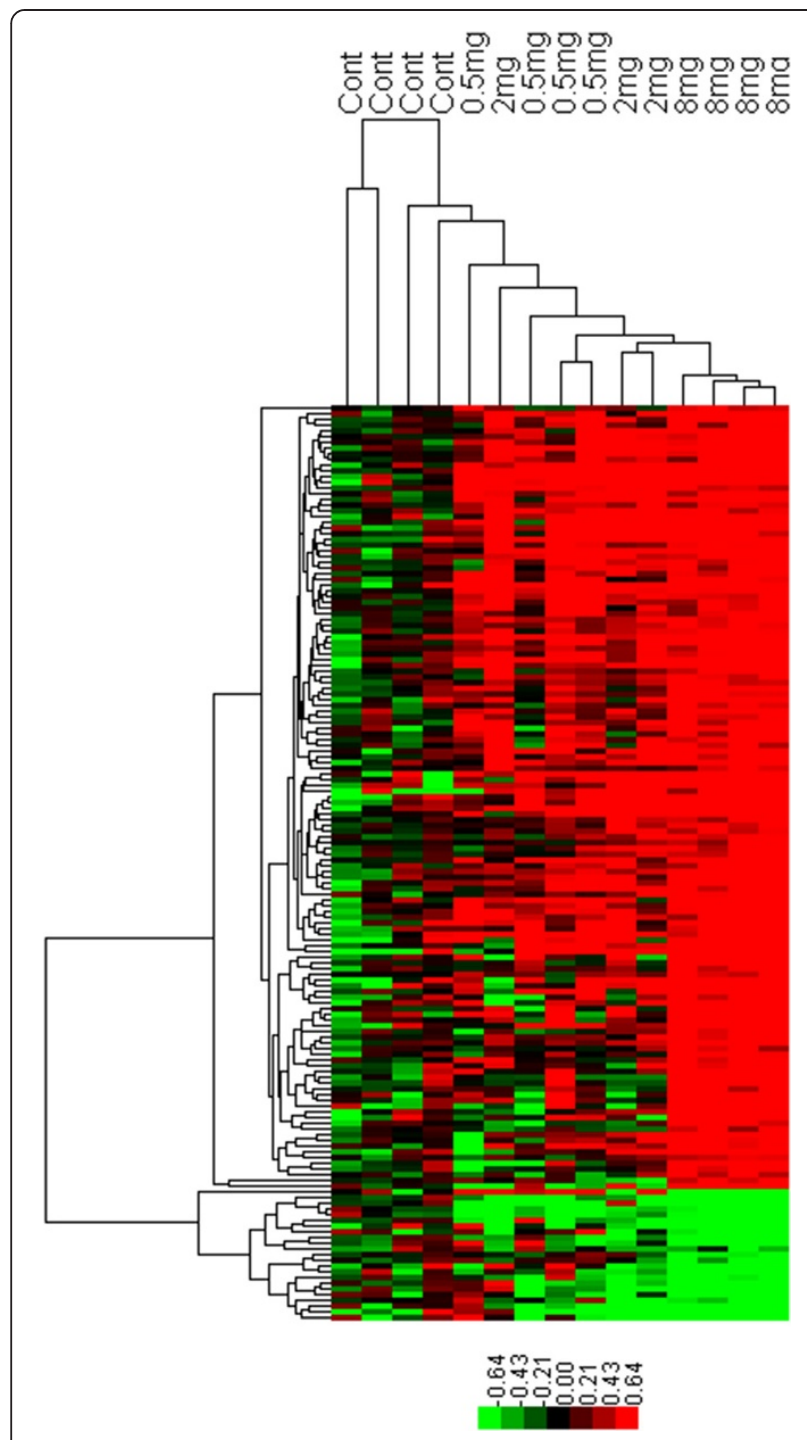

Figure 1 Hierarchical clustering analysis of genes differentially regulated by PCB 153. Analysis was performed based on $\log _{2}$-transformed ratio values of 160 genes differentially regulated, between the 8 m/kg BW PCB 153 dose and control groups. Rows represent genes and columns represent samples. Samples: Cont, Control; $0.5 \mathrm{mg}, 2 \mathrm{mg}$ and $8 \mathrm{mg}$ indicate, $0.5,2$ and $8 \mathrm{mg} / \mathrm{kg}$ BW PCB 153, respectively. Color bar indicates $\log _{2}$-transformed ratio values and corresponding colors (red, black and green for up-regulated, not changing and down regulated, respectively).

SRSF1) from the differentially regulated list (Additional file 1: Table S1) were analyzed. For most of the genes, fold-changes in expression levels with the two methods showed good correlations (Additional file 2: Figures S1A-J). Only two of the 12 genes (SRSF1 and $A P O H)$ showed poor correlations with microarray data (Additional file 2: Figures S1K and L). Confirming the microarray data, 10 out of the 12 genes were significantly up-regulated $(p<0.05$, onetailed Student's t-test) in the highest dose group (Additional file 2: Figures S1A-J). Thus, in general there is good concordance between the two methods.

\section{Functional enrichment analysis}

\section{Pathway and gene ontology analysis in DAVID}

The 165 differentially regulated genes (Additional file 1 : Table S1) were used in pathway analysis using DAVID [33] to see to most enriched pathways and biological processes. Functional annotation in DAVID showed that two of the top three significantly enriched clusters of pathways and Gene Ontology (GO) biological processes (BP) are related to lipid metabolism and DNA replication/ cell cycle (Table 1). The different significantly enriched GO BP and pathways in each of these two major enriched pathways have overlapping list of constituent genes as illustrated by the Venn diagrams for lipid metabolism (Figure 3A) and DNA metabolism related genes (Figure 3B). For example, all or the majority of the genes in DNA Replication, DNA repair and cell cycle pathways and processes are the subset of genes in the DNA metabolism biological process (Table 1, Figure 3B). As expected, Reactome DNA replication genes are a subset of Cell cycle genes, and all the genes in GO BP Cellular response to stress are a subset of the genes in Cellular response to stimulus (Table 1). The BP Cellular response to stimulus shares many of the genes (10 of 18) with DNA metabolism and Cell cycle, suggesting that the stress response activated here is related to DNA replication/ cell cycle (Figure 3B). The last significantly enriched term $(\mathrm{FDR}<1.3)$ in the last cluster contains 3 genes (KIT, BAX, and SCRIB) and is related to programmed cell death (not shown). In summary, the significantly enriched functional annotations suggest that pathways related to lipid metabolism and cell cycle were affected by PCB 153 in cod liver. The up-regulation of many DNA replication and mitotic cell cycle genes suggests proliferative effect of PCB 153. Similarly, upregulation of all the genes in the Lipid metabolic process (such as $A C A C A$ and $A C S A$ ) (Table 1) suggests lipogenic effect of PCB 153.

\section{Functional ontology analysis using MetaCore}

Analysis of the differentially regulated genes using the functional ontologies in MetaCore (GeneGo pathway map, process network and GO process) resulted in significant enrichment of many pathways and networks mainly related to lipid metabolism, cell cycle, tissue remodeling and wound repair, immune response, stress response, apoptosis and various signaling pathways (Table 2, Additional file 2: Tables S2-4). Larger number of processes and pathways were significantly enriched using MetaCore, perhaps because of differences in annotations between the databases used. Significantly 


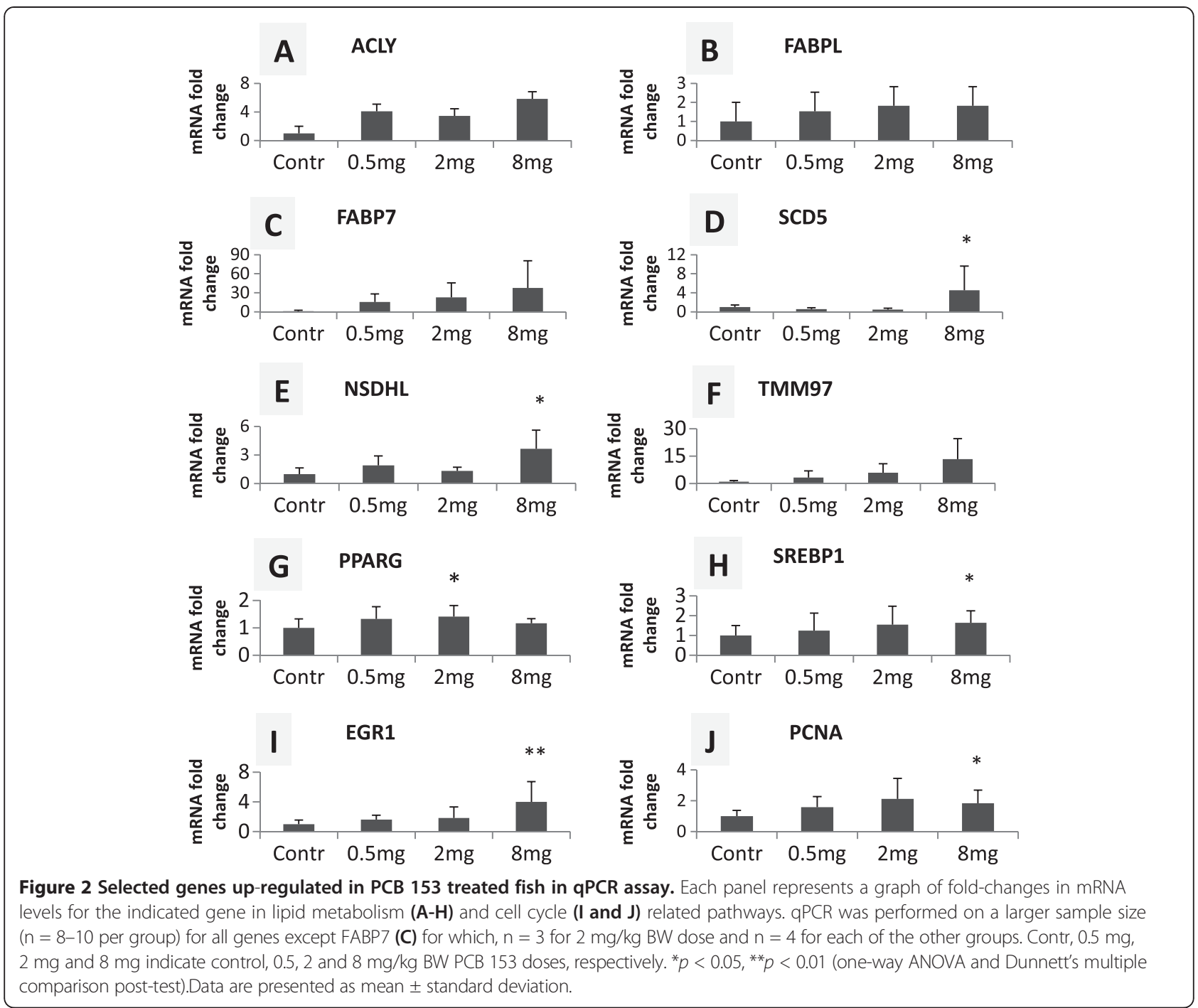

enriched top 20 GeneGo pathways, GO processes and top 20 process networks are shown in Additional file 2: Table S2, S3 and S4, respectively. Pathways and GO processes associated with lipid metabolism and DNA metabolism are among the top significantly enriched (Additional file 2: Tables S2 and S3), which is consistent with the enrichment analysis using DAVID (Table 1). The map of the top scoring pathway related to lipid metabolism (Table 2), SCAP/SREBP Transcriptional Control of Cholesterol and FA Biosynthesis, is shown in Figure 4. All the genes indicated on this pathway including genes coding for the sterol regulatory elementbinding protein 1 (SREBP1) and key genes of enzymes in fatty acid biosynthesis (e.g. ACLY, ACAC) were upregulated (Figure 2, Additional file 1: Tables S1), suggesting increased synthesis of fatty acids. SREBP1 plays key role is transcriptional activation of the lipogenic enzyme genes in the liver [34].
The organ-specific toxicity ontologies in MetaCore combine normal and pathological processes with organspecific gene markers (GeneGo). Enrichment analysis of liver-specific toxicity ontologies was performed to explore effects on liver specific functions. Again, the top enriched liver-specific Toxic Pathology Biomarkers, Toxicity Processes, Pathway Maps, GO Processes, GO Molecular Functions, GO Localizations and Drug and Xenobiotic metabolism Enzymes highlight mainly lipid metabolism and cell proliferation related events (Additional file 2: Figures S2A-G). For example, the two top enriched Toxic Pathology Biomarkers, Liver-lipid accumulation, macrovesicular $(\mathrm{FDR}=0.09)$ and Liver-degeneration $(\mathrm{FDR}=0.13)$ are pathologies that might be attributed to up-regulation of lipogenic genes (Additional file 2: Figure S2A). The most significant interaction network generated in MetaCore using the 8 genes in Liver-lipid accumulation, macrovesicular is shown in (Additional file 2: Figure S2H). This network shows 
Table 1 Annotation clusters with significantly enriched GO biological processes and pathways in PCB 153 treated samples $^{\mathrm{a}}$

\begin{tabular}{|c|c|c|c|}
\hline Category & Term & FDR & Gene/protein symbols \\
\hline Annotation Cluster 1 & Enrichment Score: 3.7 & & \\
\hline PANTHER_BP & Lipid, fatty acid and steroid metabolism & 0 & $\begin{array}{c}\text { ACSA, AUHM, PQLC3, SCD5, HMDH, GNPAT, PCY2, UD11, } \\
\text { STAR3, NSDHL, ACACA, SRBP1, FABP7N, ANXA4, PCTL, } \\
\text { GDPD2, ACLY, PPARG, FABPL, DHB12 }\end{array}$ \\
\hline GOTERM_BP & Lipid metabolic process & 0.2 & $\begin{array}{c}\text { ACSA, SCD5, APOH, HMDH, GNPAT, PCY2, KIT, UD11, } \\
\text { GPAT3, STAR3, NSDHL, ACACA, SRBP1, BAX, PLB1, } \\
\text { GDPD2, ACLY, MK14, PPARG, DHB12 }\end{array}$ \\
\hline GOTERM_BP & Lipid biosynthetic process & 4.2 & ACSA, GPAT3, STAR3, ACACA, NSDHL, SCD5, ACLY, HMDH, PCY2, DHB12 \\
\hline Annotation Cluster 2 & Enrichment Score: 2.2 & & \\
\hline GOTERM_BP & DNA metabolic process & 0 & $\begin{array}{c}\text { DNMT1, BAF, BLM, TYDP1, FEN1, NUP98, RTEL1, } \\
\text { MCM3, PPIA, MCM5, RMI1, DPOA2, BAX, } \\
\text { DPOD1, KC1E, FOS, PCNA, RECQ4 }\end{array}$ \\
\hline PANTHER_BP & DNA metabolism & 0.1 & $\begin{array}{l}\text { MCM5, DPOA2, DNMT1, DPOD1, BLM, TYDP1, KC1E, } \\
\text { FEN1, PCNA, RECQ4, RTEL1, MCM3 }\end{array}$ \\
\hline KEGG_PW & DNA replication & 0.2 & MCM5, DPOA, DPOD1, FEN1, PCNA, MCM3 \\
\hline REACT_PW & DNA Replication & 0.2 & MCM5, PSMD3, DPOA2, DPOD1, FEN1, PCNA, PSB7, MCM3 \\
\hline GOTERM_BP & DNA replication & 0.5 & MCM5, RMI1, DPOA2, DPOD1, BLM, FEN1, NUP98, PCNA. MCM3 \\
\hline PANTHER_BP & DNA repair & 0.5 & DPOD1, BLM, TYDP1, KC1E, FEN1, PCNA, RECQ4, RTEL1 \\
\hline GOTERM_BP & Cellular response to stress & 0.9 & $\begin{array}{c}\text { SYAC, BLM, E2AK2, TYDP1, FEN1, RTEL1, ETV5, SRBP1, BAX, } \\
\text { DPOD1, KC1E, MK14, FOS, PCNA, RECQ4 }\end{array}$ \\
\hline PANTHER_BP & DNA replication & 1.1 & MCM5, DPOA2, DPOD1, BLM, FEN1, PCNA, MCM3 \\
\hline GOTERM_BP & Cellular response to stimulus & 1.8 & $\begin{array}{l}\text { SYAC, BLM, E2AK2, TYDP1, FEN1, RTEL1, ETV5, UD11, SRBP1, } \\
\text { BAX, DPOD1, KC1E, ERBB3, MK14, PPARG, FOS, PCNA, RECQ4 }\end{array}$ \\
\hline GOTERM_BP & DNA-dependent DNA replication & 3.0 & MCM5, DPOD1, BLM, FEN1, MCM3 \\
\hline REACT_PW & Cell Cycle, Mitotic & 4.5 & MCM5, PSMD3, DPOA2, DPOD1, KC1E, KNTC1, FEN1, NUP98, PCNA, PSB7, MCM3 \\
\hline Annotation Cluster 3 & Enrichment Score: 2.0 & & \\
\hline GOTERM_BP & Macromolecule localization & 2.4 & $\begin{array}{l}\text { APOH, GNPTA, SNX12, KPCB, NUP98, SNX25, DVL1L, } \\
\text { VPS53, STAR3, EZRI, SNX18, DPOA2, BAX, YIF1A, GOT1B, } \\
\text { DUS16, APOM, PPARG, RFIP2, PCNA, FABL }\end{array}$ \\
\hline
\end{tabular}

${ }^{a}$ Enrichment analysis was performed for functional categories GO BP (PANTHER_BP_ALL and GOTERM_BP_ALL) and pathway (KEGG and Reactome) using DAVID tools (functional annotation cluster). Only significant annotation terms (FDR $<5 \%$ ) are shown. All the genes were up-regulated except four (KIT, UD11, PLB1, BAF, E2AK2), which were down regulated.
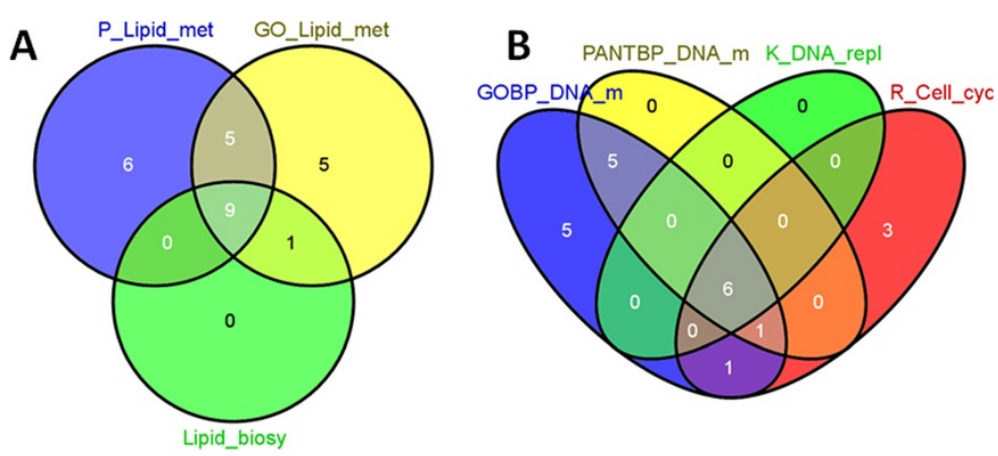

Figure 3 Venn diagrams showing overlapping genes in enriched lipid metabolism (A) and DNA metabolism/ cell cycle (B) pathways and processes in Table 1. Abbreviations for terms in Table 1: P_Lipid_met, PANTHER_BP Lipid, fatty acid and steroid metabolism; GO_Lipid_met, GOTERM_BP Lipid metabolic process; Lipid_biosy, GOTERM_BP Lipid biosynthetic process. GO_DNA_met, GOTERM_BP DNA metabolic process; GO_DNA_repl, GOTERM_BP DNA replication; Resp_Stim, GOTERM_BP Cellular response to stimulus; R_Cell_cy, Reactome_Pathway, Cell Cycle, Mitotic. 
Table 2 Significantly enriched top 20 GeneGo pathways ${ }^{a}$

\begin{tabular}{|c|c|c|c|}
\hline Maps & p-value & FDR & Gene/protein symbols \\
\hline $\begin{array}{l}\text { SCAP/SREBP Transcriptional Control of } \\
\text { Cholesterol and FA Biosynthesis }\end{array}$ & $6.0 \mathrm{E}-09$ & 0 & $\begin{array}{l}\text { HMDH, SREBP1 (Golgi membrane), ACLY, ACSA, } \\
\text { SCD5, SREBP1 precursor, SREBP1 (nuclear), ACACA }\end{array}$ \\
\hline $\begin{array}{l}\text { Regulation of lipid metabolism_Regulation } \\
\text { of lipid metabolism via LXR, NF-Y and SREBP }\end{array}$ & 2.1E-05 & 0 & $\begin{array}{l}\text { SREBP1 (Golgi membrane), ACLY, } \\
\text { SREBP1 precursor, SREBP1 (nuclear), ACACA }\end{array}$ \\
\hline Adiponectin in pathogenesis of type 2 diabetes & $1.2 \mathrm{E}-04$ & 0 & $\begin{array}{l}\text { SREBP1 precursor, p38alpha (MAPK14), } \\
\text { SREBP1 (nuclear), ACACA }\end{array}$ \\
\hline Immune response_Oncostatin M signaling via MAPK in mouse cells & 2.6E-04 & 0 & EGR1, PPAR-gamma, p38 MAPK, c-Fos \\
\hline Development_Role of IL-8 in angiogenesis & $2.8 \mathrm{E}-04$ & 0 & $\begin{array}{l}\text { HMDH, SREBP1 (Golgi membrane), } \\
\text { SREBP1 precursor, SREBP1 (nuclear), c-Fos }\end{array}$ \\
\hline Immune response_Oncostatin M signaling via MAPK in human cells & 3.2E-04 & 0 & EGR1, PPAR-gamma, p38 MAPK, c-Fos \\
\hline Development_Gastrin in differentiation of the gastric mucosa & 3.5E-04 & 0 & PKC-beta, EGR1, PKC, cPKC (conventional) \\
\hline Development_EGFR signaling pathway & 4.2E-04 & 0 & PKC-beta, p38 MAPK, p38alpha (MAPK14), c-Fos, Bax \\
\hline $\begin{array}{l}\text { Regulation of lipid metabolism_Regulation } \\
\text { of fatty acid synthase activity in hepatocytes }\end{array}$ & $6.1 \mathrm{E}-04$ & 0 & SREBP1 (Golgi membrane), SREBP1 precursor, SREBP1 (nuclear) \\
\hline $\begin{array}{l}\text { Regulation of lipid metabolism_Insulin } \\
\text { regulation of fatty acid methabolism }\end{array}$ & $1.2 \mathrm{E}-03$ & 0 & $\begin{array}{l}\text { SREBP1 (Golgi membrane), ACLY, } \\
\text { SREBP1 precursor, SREBP1 (nuclear), ACACA }\end{array}$ \\
\hline SREBP1 cross-talk with PXR, CAR and LXR & 1.6E-03 & 0 & SREBP1 (Golgi membrane), SREBP1 precursor, SREBP1 (nuclear) \\
\hline G-protein signaling_Ras family GTPases in kinase cascades (schema) & 1.6E-03 & 0 & p38 MAPK, p38alpha (MAPK14), c-Fos \\
\hline DNA damage_ATM / ATR regulation of G2 / M checkpoint & 1.6E-03 & 0 & BLM, p38alpha (MAPK14), GADD45 beta \\
\hline Cell cycle_Transition and termination of DNA replication & 2.0E-03 & 0.1 & PCNA, FEN1, POLD cat (p125) \\
\hline Apoptosis and survival_p53-dependent apoptosis & $2.2 \mathrm{E}-03$ & 0.1 & p38alpha (MAPK14), GADD45 beta, Bax \\
\hline Renin-Angiotensin-Aldosterone System & 2.3E-03 & 0.1 & PKC-beta, CaMK I, p38alpha (MAPK14), c-Fos \\
\hline Neuroprotective action of lithium & $2.4 \mathrm{E}-03$ & 0.1 & p38 MAPK, p38alpha (MAPK14), Dsh, Bax \\
\hline SREBP1 cross-talk with PXR, CAR and LXR/ Rodent version & 2.6E-03 & 0.1 & SREBP1 (Golgi), SREBP1 precursor, SREBP1 (nuclear) \\
\hline Development_Inhibition of angiogenesis by PEDF & 2.6E-03 & 0.1 & PPAR-gamma, p38 MAPK, Bax \\
\hline DNA damage_ATM/ATR regulation of G1/S checkpoint & 2.9E-03 & 0.1 & PCNA, BLM, GADD45 beta \\
\hline
\end{tabular}

${ }^{\mathrm{a}}$ Only the significantly enriched top 20 pathways are shown here, with the full list presented in Additional file 2: Table S2.

potential involvement of the genes in development of pathology related to lipid accumulation. Similarly, the top liver-specific Toxicity Processes, Steatosis, development $(\mathrm{FDR}=0.15)$ and Cell cycle, processes involved in S-phase $(\mathrm{FDR}=0.68)$ (Additional file 2: Figure S2B) are related to lipid accumulation and cell proliferation, respectively. The list of liver-specific enriched Maps and GO processes (Additional file 2: Figures S2C and D) are similar to the list in Additional file 2: Table S2 and S3, respectively. GO molecular functions and localizations also reflect the top enriched lipid metabolism and cell cycle pathways (Additional file 2: Figures S2E and F). The analysis also showed enrichment of pathways mediated by AhR and the nuclear receptors (CAR, FXR and LXR and PXR) associated with Drug and Xenobiotic metabolism Enzymes (Additional file 2: Figure S2G). In mammals, the nuclear receptors LXR, CAR and PXR are involved in regulation of lipid metabolism, mainly through cross-talk with SRBP1 pathway (See Table 2) [35]. Enrichment of PXR/ CAR mediated pathway is expected as PCB 153 is known to activate these receptors [5]. Surprisingly, AhR mediated regulation of Drug and Xenobiotic metabolism Enzymes is the top enriched pathway with 17 genes involved (Additional file 2: Figure S2G), although PCB 153 does not activate AhR. The 17 genes in this pathway are CCL4, CNTNAP1, FOS, HMGCR, ITPKB, MAPK14, MYO1D, PCNA, POLA2, PSMA5, SREBF1 and TEAD3. The AhR signaling pathway may however interact with these genes indirectly and the enrichment here may reflect its diverse biological functions and possible alternative mechanisms involved.

\section{Interactome and network analysis using MetaCore}

The MetaCore Interactome analysis tool was used to explore statistically significant interactions of the differentially regulated genes (Additional file 1: Table S1). The analysis option "Transcription Factors" was used to perform enrichment analysis of interactions based on transcriptional regulation mechanisms, which generated a list of significantly enriched (FDR $<0.05)$ transcription factors (Additional file 2: Table S5). Here, enrichment shows that a significantly higher proportion of genes in the up-loaded list (compared to the total number of genes in the whole database for the organism) show interactions with the transcription factor. Many transcription factors involved 


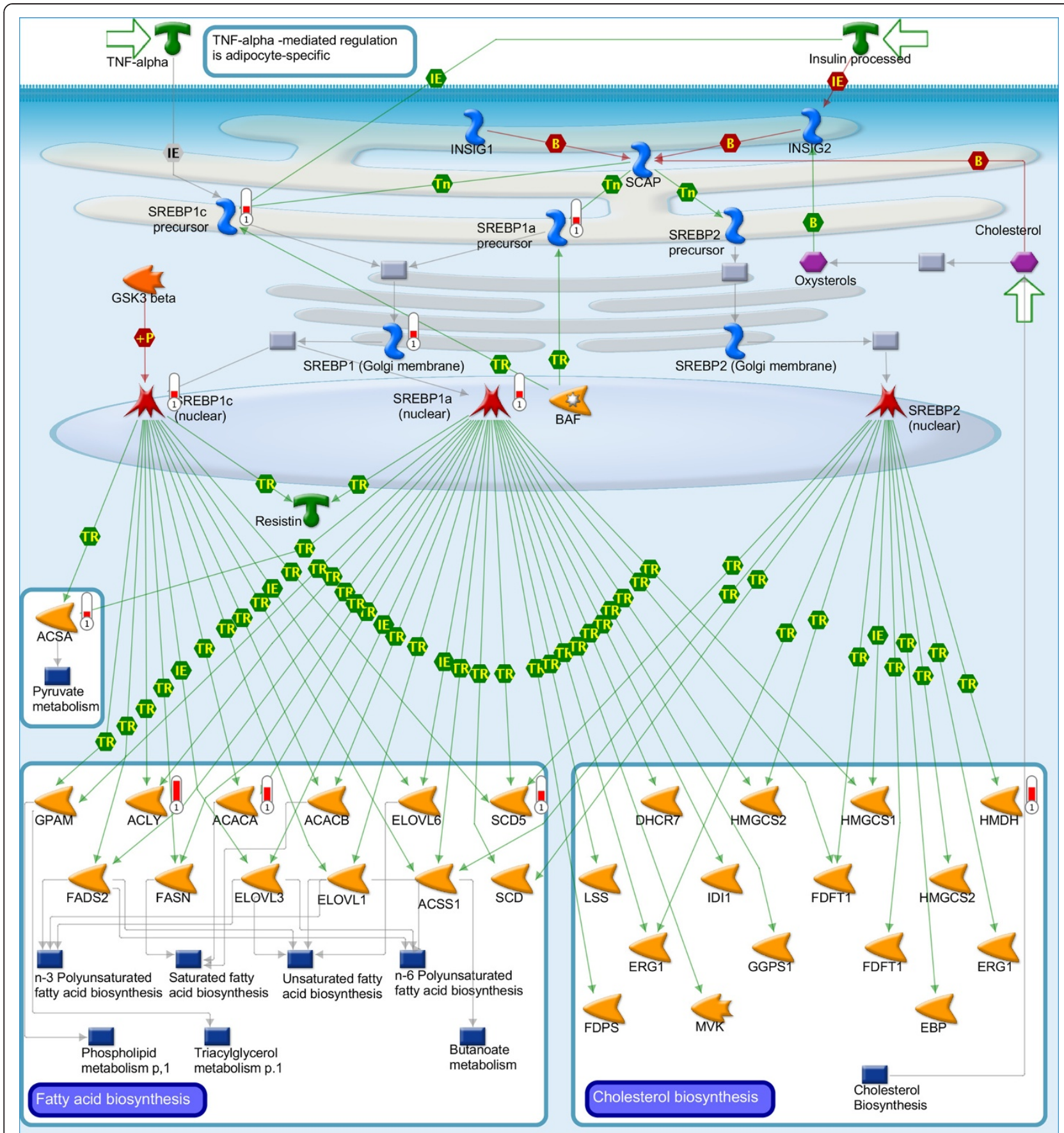

Figure 4 Map of SCAP/SREBP Transcriptional Control of Cholesterol and FA Biosynthesis. This is the top enriched GeneGo pathway showing the differentially regulated genes (all up-regulated) indicated by thermometer-like symbols in red. For detailed legend see Figure $2 \mathrm{SH}$ in Additional file 2.

in regulation of the cell cycle (e. g. E2F1, E2F2, E2F3, E2F4, E2F6, EGR1and EGR2) and lipid metabolism (N220, SREBP1 and SREBP2) were significantly enriched (Additional file 2: Table S5), consistent with the top enrichment of these two pathways. Interestingly, the top enriched transcription factor N220 (ZNF638) is a regulator of adipocyte differentiation and the lipogenic transcription factors
PPARG and SREBP1[36]. Among the transcription factors enriched, early growth response 1 (EGR1) and Sterol regulatory element-binding protein 1 (SREBP1) were also upregulated in this study (Additional file 1: Table S1, Figure 2).

To build a network of interaction among the differentially regulated genes in our experiment, the network building tool in MetaCore with the "Direct interaction" 
algorithm was used, which resulted in a statistically significant (FDR < 0.05) network (Figure 5). Remarkably, this network reveals regulatory relationships between the transcription factors and their target genes in the differentially regulated list, highlighting activation of the two main pathways lipid metabolism and cell cycle. Particularly well illustrated is the interactions of EGR1, PPARG and SRBP1 transcription factors that result in activation of the lipogenic genes $H M D H$, fatty acid binding protein, $A C A C A, A C L Y, S C D 5$ and ACSA, which is supported by the top enriched canonical pathway (Figure 4). The network suggests activation of the transcription factors through the MAPK (Mitogen-activated protein kinase) pathway and potential cross-talk between the cell proliferation and lipogenic pathways. The gene coding for the transcription factor EGR1 is one of the most upregulated in this experiment (Additional file 1: Table S1, Figure 2), which may suggest its importance in the regulation of the differentially regulated genes. As indicated EGR1 appears to occupy a central role in the network as it is possibly activated via the p38 MAPK signaling pathway, and interacts downstream with both proliferation and lipogenic transcription factors (Figure 5). EGR1, known to regulate many genes related to cell proliferation, apoptosis and immune response $[37,38]$, has also been implicated in regulation of cholesterol biosynthesis genes [39], supporting the interactions depicted in the network shown here.

\section{Gene Set Enrichment Analysis (GSEA)}

GSEA uses the whole set of genes without pre-selection to determine if a pre-defined set of genes constituting a functional category show significant, concordant differences in expression between two biological states [32]. GSEA was performed here as an independent and complementary method to the pathway analyses using DAVID and MetaCore, which were performed only on the differentially regulated genes. GSEA is suited for modest changes in gene expression since it draws its statistical power from concordant differential expression of many genes within a gene set and their correlation to one of the two biological states under comparison [40]. In this analysis, all cod genes on the array that could be mapped to putative human orthologs were ranked based on relative expression correlation from highest absolute levels in the PCB 153 groups to the lowest levels. The predominant gene sets significantly enriched are the Reactome gene sets related to DNA metabolism and cell cycle (Table 3, Additional file 3: Table S6). Table 3 shows the significantly enriched gene sets of the Reactome (only the top 20), GenMAPP (Gene Map Annotator and

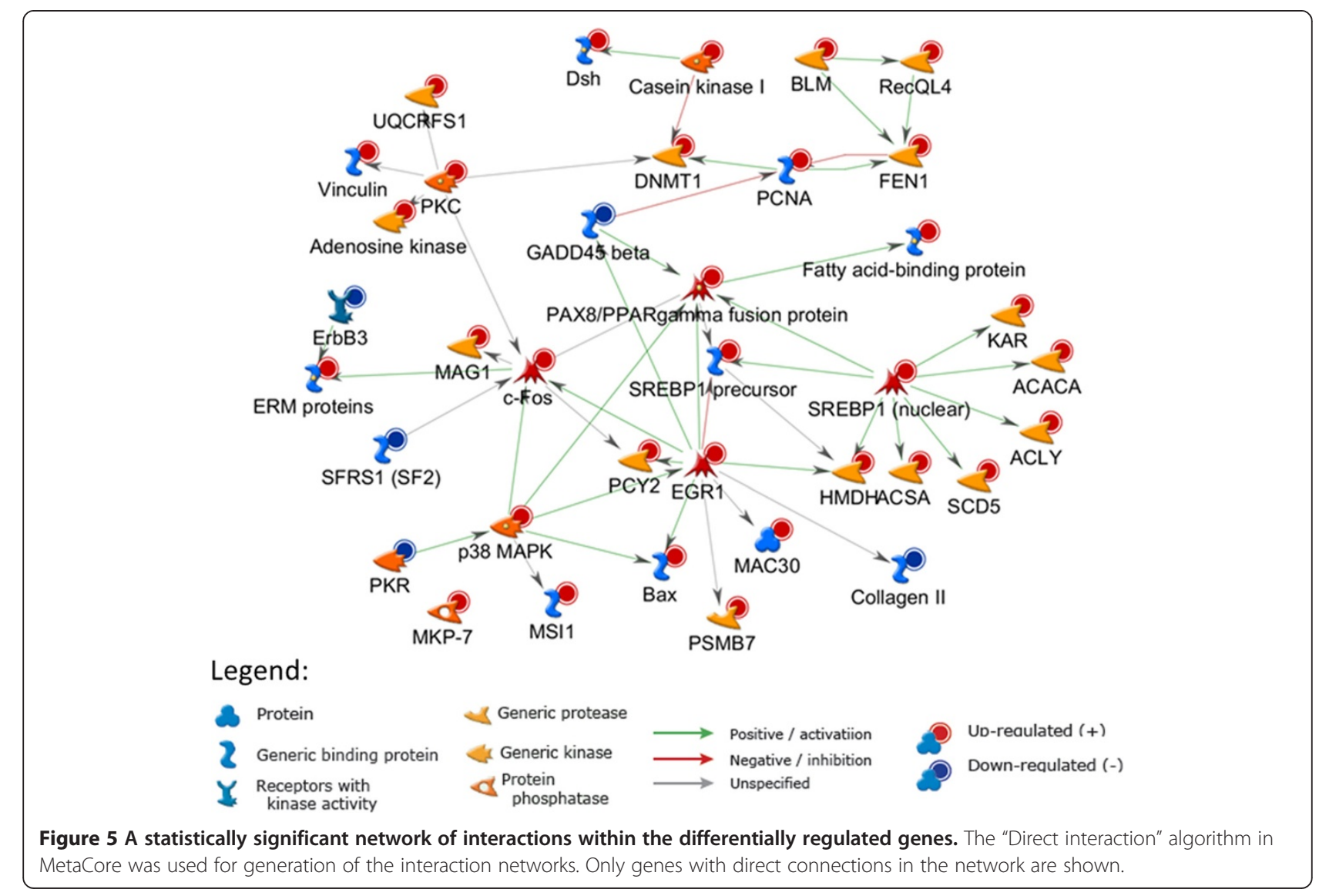


Table 3 Gene sets enriched in PCB 153 treated samples ${ }^{a}$

\begin{tabular}{|c|c|c|c|c|}
\hline Reactome gene set & SIZE & NES & NOM p-val & FDR q-val \\
\hline SYNTHESIS_OF_DNA & 61 & 2.0 & $3.1 \mathrm{E}-03$ & 0.09 \\
\hline DNA_STRAND_ELONGATION & 25 & 1.9 & $1.4 \mathrm{E}-02$ & 0.05 \\
\hline M_G1_TRANSITION & 52 & 1.9 & $7.2 \mathrm{E}-03$ & 0.04 \\
\hline S_PHASE & 74 & 1.9 & 7.1E-03 & 0.05 \\
\hline ASSEMBLY_OF_THE_PRE_REPLICATIVE_COMPLEX & 40 & 1.9 & 0 & 0.04 \\
\hline ACTIVATION_OF_THE_PRE_REPLICATIVE_COMPLEX & 26 & 1.9 & $3.0 \mathrm{E}-02$ & 0.04 \\
\hline ORC1_REMOVAL_FROM_CHROMATIN & 41 & 1.8 & 0 & 0.05 \\
\hline ACTIVATION_OF_NF_KAPPAB_IN_B_CELLS & 34 & 1.8 & $6.1 \mathrm{E}-03$ & 0.06 \\
\hline SCF_BETA_TRCP_MEDIATED_DEGRADATION_OF_EMI1 & 25 & 1.8 & 7.2E-03 & 0.05 \\
\hline G1_S_TRANSITION & 76 & 1.8 & $1.3 \mathrm{E}-02$ & 0.05 \\
\hline ER_PHAGOSOME_PATHWAY & 30 & 1.7 & 4.1E-03 & 0.06 \\
\hline CDT1_ASSOCIATION_WITH_THE_CDC6_ORC_ORIGIN_COMPLEX & 32 & 1.7 & $3.0 \mathrm{E}-03$ & 0.05 \\
\hline TRNA_AMINOACYLATION & 26 & 1.7 & 2.7E-02 & 0.05 \\
\hline SCFSKP2_MEDIATED_DEGRADATION_OF_P27_P21 & 31 & 1.7 & $1.1 \mathrm{E}-02$ & 0.05 \\
\hline MITOTIC_G1_G1_S_PHASES & 90 & 1.7 & $1.6 \mathrm{E}-02$ & 0.05 \\
\hline VIF_MEDIATED_DEGRADATION_OF_APOBEC3G & 25 & 1.7 & $1.0 \mathrm{E}-02$ & 0.05 \\
\hline TRIGLYCERIDE_BIOSYNTHESIS & 30 & 1.7 & $9.1 \mathrm{E}-03$ & 0.05 \\
\hline ACTIVATION_OF_ATR_IN_RESPONSE_TO_REPLICATION_STRESS & 28 & 1.7 & $4.3 \mathrm{E}-02$ & 0.06 \\
\hline GLOBAL_GENOMIC_NER_GG_NER & 25 & 1.7 & 1.7E-02 & 0.06 \\
\hline GenMAPP gene set & SIZE & NES & NOM p-val & FDR q-val \\
\hline DNA_REPLICATION_REACTOME & 29 & 2.0 & 0.021 & 0.03 \\
\hline AMINOACYL_TRNA_BIOSYNTHESIS & 15 & 1.9 & 0.020 & 0.03 \\
\hline G1_TO_S_CELL_CYCLE_REACTOME & 41 & 1.6 & 0.058 & 0.20 \\
\hline GLYCEROPHOSPHOLIPID_METABOLISM & 32 & 1.6 & 0.020 & 0.21 \\
\hline KEGG gene set & SIZE & NES & NOM p-val & FDR q-val \\
\hline DNA_REPLICATION & 30 & 1.9 & 0.027 & 0.04 \\
\hline NUCLEOTIDE_EXCISION_REPAIR & 31 & 1.6 & 0.025 & 0.24 \\
\hline OXIDATIVE_PHOSPHORYLATION & 50 & 1.6 & 0.047 & 0.18 \\
\hline
\end{tabular}

anly significantly enriched (FDR q-value $<0.25$ ) top 20 Reactome gene sets and all significant GenMAPP and KEGG gene sets are shown. Gene sets are ranked by normalized enrichment score (NES). SIZE and NOM p-val, indicate number of core genes in the enriched gene set and Nominal p-value, respectively.

Pathway Profiler) and KEGG (Kyoto Encyclopedia of Genes and Genomes) databases. Gene sets related to lipid metabolism, triglyceride biosynthesis and glycerophospholipid metabolism were among the significantly enriched (Additional file 3: Table S6). Many more Reactome gene sets (total 56) were significantly enriched (FDR $<0.25$ ), compared to only 4 and 3 for GenMAPP and KEGG, respectively (Table 3, Additional file 3: Table S6). Most of the Reactome gene sets are associated with DNA repair, replication and cell cycle (Additional file 3: Table S6). Other top enriched Reactome gene sets are mainly related to immune response, apoptosis, respiratory electron transport, translation and circadian clock. The top significantly enriched gene sets (Table 3, Additional file 3: Table S6) are largely similar to the enriched pathways using DAVID and MetaCore (Tables 1 and 2,
Additional file 2: Tables S2, S3 and S4, Additional file 3: Tables S6), which mainly highlighted pathways associated with DNA metabolism, cell cycle, lipid metabolism, apoptosis, immune response and, stress response. In Figure 6, enrichment plots for top enriched Reactome pathways, synthesis of DNA (A) with the corresponding leading edge genes (B), and triglyceride biosynthesis (C), with the corresponding leading edge genes (D) are shown. Genes in the enriched gene sets have higher enrichment scores (ES) and tend to have hits clustered towards the top of the sorted gene list (Figures 6A and $\mathrm{C})$, suggesting their modulation by $\mathrm{PCB} 153$. The leading edge list in the top gene set synthesis of DNA (Figure 6B) contains most of the genes in the Reactome pathways DNA replication and Cell cycle enriched in pathway analysis using DAVID (Table 1). Similarly, the leading edge list in the 


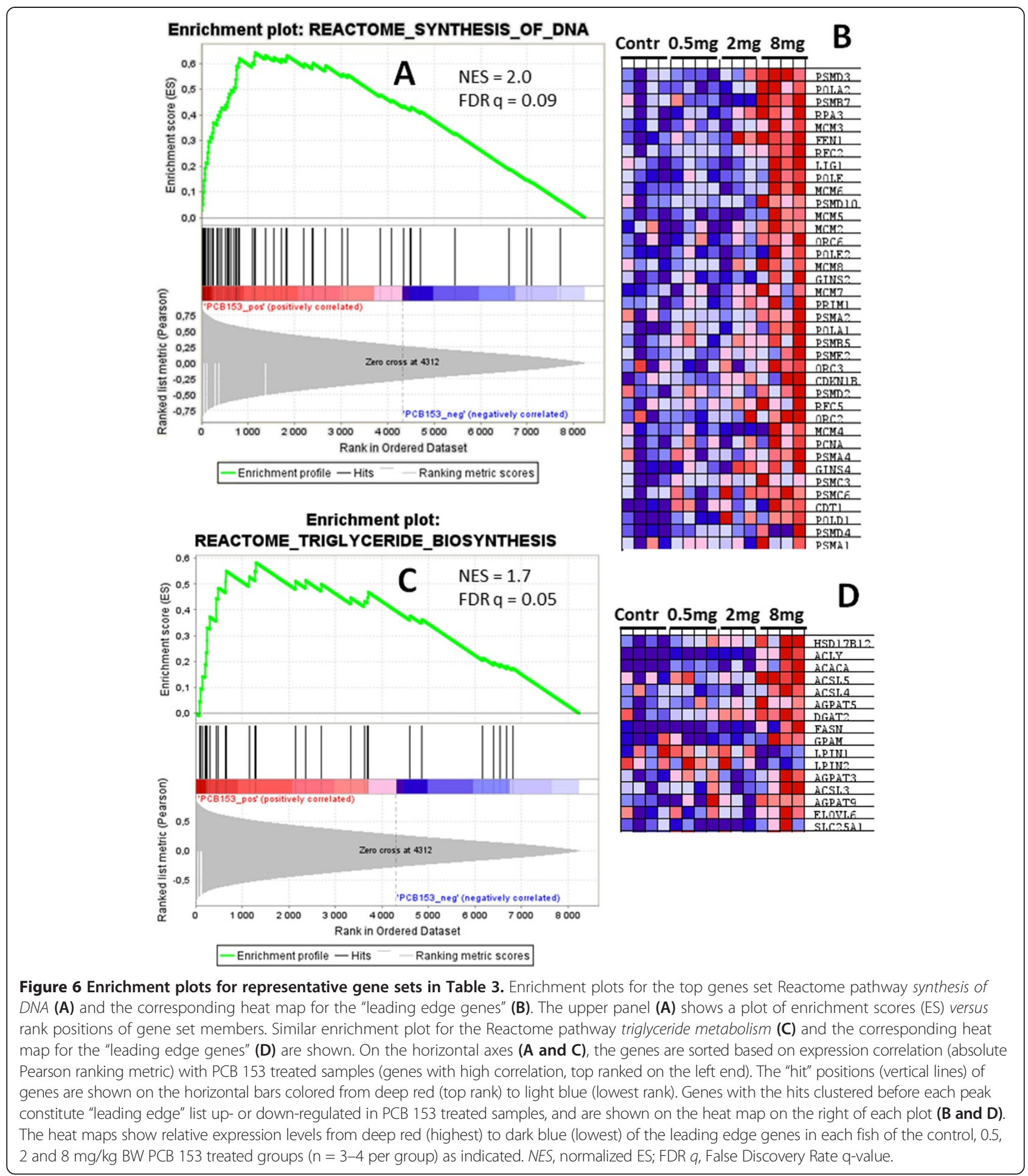

gene set triglyceride biosynthesis (Figure 6D) consists of genes coding for enzymes in de novo synthesis of glycerolipids such as ACLY, ACACA, FASN, GPAT, AGPAT3, AGPAT5, and AGPAT9, some of which are also present in the enriched lipid synthesis biological processes in DAVID (Table 1). The up-regulation of these genes may indicate increased lipid synthesis in PCB 153 treated fish liver, in agreement with the results from analysis using DAVID and MetaCore.

In summary, pathways, processes and networks related to DNA replication, cell cycle and lipid metabolism were consistently enriched using the different methods of 
analysis employed. The coordinated up-regulation of DNA replication and cell cycle related genes suggests that PCB 153 increases cell proliferation in the liver of cod. In agreement with our results, PCB 153 has been shown to increase hepatocyte proliferation and act as liver tumor promoter in rats [10]. Some of the upregulated genes coding for enzymes such as ACLY, ACACA and FASN (Figure 4, Figure 6D) are important in de novo lipid biosynthesis pathway [41], suggesting increased lipogenesis in PCB 153 treated fish. For example, ACACA catalyzes the rate-limiting reaction in the synthesis of long-chain fatty acids [42].

Transcriptional activation of both cell cycle and lipogenic genes has been observed during adipogenesis in mammalian model systems [43]. It is not clear if the simultaneous up-regulation of cell cycle and lipogenic genes in cod liver is mechanistically related to these adipogenesis processes in mammalian systems. It is possible that up-regulation of genes associated with cell cycle progression is related to activation of immune response pathways observed here or liver tumor promoting effects of PCB 153, as shown in rats [10]. However, the transcriptional activation of lipogenic genes in cod liver treated by PCB 153 appears to be supported by recent studies that have documented adipogenic effects of PCBs and other environmental chemicals $[11,12,15]$. In mice, it was reported that bisphenol A increased hepatic expression of lipogenic genes and lipid accumulation [44]. In pre-adipogenic fibroblast 3T3-L1 cell culture studies, PCB 153 and other chemicals have also been shown to increase transcription of lipogenic marker genes, lipid accumulation and adipogenic differentiation $[16,19,20]$. A recent study showed that mice fed with a combination of PCB 153 and high-fat-diet showed increased visceral adiposity, hepatic steatosis, plasma adipokines, and upregulation of hepatic lipid biosynthesis and down- regulation of $\beta$-oxidation genes [18]. In our experiment, significant changes were not observed in expression of $\beta$-oxidation genes, although mRNA levels of the key gene of this pathway, liver carnitine palmitoyltransferase 1A $(C P T 1 A)$ showed a non-significant (FDR > 10\%) decrease (expression ratio 0.61 in the highest dose group). Phospholipase B1 (PLB1) among the down-regulated genes (Additional file 1: Table S1) may also be related to lipid degradation. Our hypothesis that transcriptional activation of lipid biosynthesis genes could be attributed to lipogenic effect of PCB 153 is supported by these studies. Although species differences should be considered in the comparison with mammalian systems, our results appear to be consistent with conservation of lipid metabolism and adipogenesis processes in fish and mammals $[45,46]$. Indeed, zebrafish (D. rerio) is increasingly used as a model organism in research on obesity and related metabolic diseases [21-23]. Thus, our results showing increased transcription of lipogenic genes in the liver of cod treated with PCB 153 can provide relevant insights into potential effects in mammals.

Apart from cell cycle and lipid metabolism pathways, other significantly enriched pathways are mainly associated with immune response, apoptosis, stress response and tissue remodeling, and they are probably related to general toxicity by PCB 153. Some of the genes in these pathways (e.g. stress response and apoptosis) have also significant overlap with the genes in lipid metabolism and cell cycle pathways (Tables 1 and 2, Additional file 2: Table S2). Apoptosis and immune response pathways have been previously reported to be affected in transcriptomics and proteomics studies in response to environmental contaminants in cod and other fish [26,28,47-50]. Studies in higher organisms have also shown that PCB 153 can modulate the immune system $[8,51]$.

\section{Conclusions}

Gene expression analysis in the liver of cod treated with PCB 153 indicated transcriptional activation of genes mainly associated with cell cycle, DNA replication, lipid metabolism, immune response, apoptosis and stress response pathways. The constituent genes in the two major affected pathways, cell cycle and lipid biosynthesis were mostly up-regulated, suggesting increased cell proliferation and lipid synthesis in PCB 153 treated cod liver. The results provide new insights into mechanisms of toxicity of PCB 153.

\section{Methods}

\section{Fish exposure and sampling}

Fish exposure and sampling has been described previously [9]. Briefly, juvenile Atlantic cod of mixed genders (G. morhua) approximately 1.5 years old with 220-530 g of body weight (BW) were kept in $500 \mathrm{~L}$ tanks and supplied with continuously flowing seawater at temperature of $10^{\circ} \mathrm{C}$. A $12: 12 \mathrm{~h} \mathrm{light/dark} \mathrm{cycle} \mathrm{was} \mathrm{used} \mathrm{and} \mathrm{the} \mathrm{fish}$ were fed daily for $8 \mathrm{~h}$ with commercial pellets (EWOS, Bergen, Norway). After acclimation for 6 days, the fish were injected (i.p.) with $0,0.5,2$ or $8 \mathrm{mg} / \mathrm{kg}$ body weight PCB $153\left(2,2^{\prime}, 4,4^{\prime}, 5,5^{\prime}\right.$ - hexachlorobiphenyl) (98.3\% purity, Chem Service, West Chester, USA). The doses were given in two injections, half of the dose on the first day and the second half after one week. PCB 153 was dissolved in a vehicle of $20 \%$ acetone and $80 \%$ soybean oil. The control fish were injected with the vehicle only. The fish were sacrificed 14 days after the first injection and liver samples were frozen in liquid nitrogen and stored at $-80^{\circ} \mathrm{C}$ until use. At the end of the experiment, chemical analysis showed liver burden of PCB 153 increased to approximately 4 times the maximum total body burden from the injected doses [9], reflecting the tendency of highly lipophilic compounds like PCBs to accumulate 
in the lipid-rich liver of the cod. The exposure experiment was approved by the National Animal Research Authority.

\section{RNA extraction}

Total RNA isolation from liver samples, determination of concentration and quality assessment was performed as described before [28]. RNA samples from vehicle control, 0.5 and 2 and $8 \mathrm{mg} / \mathrm{kg}$ BW PCB 153 doses $(\mathrm{n}=3$ for $2 \mathrm{mg} / \mathrm{kg} \mathrm{BW}$ dose, and $\mathrm{n}=4$ for each of the other groups) were submitted to Roche NimbleGen for labeling and hybridization.

\section{Microarray design and hybridization}

Microarray design and hybridization has been described previously [28]. Briefly, Atlantic cod $135 \mathrm{~K}$ oligonucleotide arrays were designed from a $44 \mathrm{k}$ cDNA collection [27] and manufactured by Roche Nimblegen (Madison, WI). The array contains 125,825 probes derived from the G. morhua sequences (3 or more probes per cDNA sequence) and 11,779 Nimblegen control probes. RNA samples from control fish (n = 4), $0.5 \mathrm{mg} / \mathrm{kg}$ BW PCB 153 ( $\mathrm{n}=4), 2 \mathrm{mg} / \mathrm{kg}$ BW PCB $153(\mathrm{n}=3)$ and $8 \mathrm{mg} / \mathrm{kg}$ BW PCB $153(\mathrm{n}=4)$ doses were submitted to Roche NimbleGen for hybridization. For each sample, double strand cDNA labelled with Cy3 was hybridized on the array according to protocols in Gene Expression User Guide (Roche NimbleGen, Madison, WI).

\section{Microarray data analysis}

Filtering and analysis of differential regulation was performed essentially as described before [28], with the following modifications. Expression ratios were (calculated by dividing fluorescent intensity values in each sample by average intensity value of control sample), $\log _{2}$-transformed and differentially regulated genes were identified using Significance Analysis of Microarrays (SAM) [52] implemented in J-Express [53] (Molmine, Bergen, Norway). For identification of differentially regulated genes, the control and $8 \mathrm{mg} / \mathrm{kg}$ BW PCB 153 dose groups were compared using SAM, and genes were considered differentially regulated at a maximum False Discovery Rate (FDR) of $10 \%$. With this threshold, a total of 160 (139 up-regulated and 21 down-regulated) genes were found to be differentially regulated. No differentially expressed genes were detected at FDR $<5 \%$. Therefore, a less stringent 10\% FDR cut-off was chosen for differential expression. No genes met the criteria for differential regulation using SAM with the same cut-off (FDR maximum of 10\%) for the 0.5 and $2 \mathrm{mg} / \mathrm{kg}$ BW PCB 153 doses. Unsupervised hierarchical clustering analysis of the 160 differentially regulated genes was performed using Cluster3 software with average linkage distance metric [54]. Venn diagrams were drawn using an online tool Venny http://bioinfogp.cnb.csic.es/tools/ venny/). The array data have been deposited in NCBI's
Gene Expression Omnibus (GEO) database (GEO accession GSE43733).

\section{Annotation and pathway analysis}

For pathway analysis using the well annotated mammalian genome and proteome databases and tools, the Atlantic cod genes were mapped to human orthologs as described before [28]. Pathway enrichment analysis was performed in DAVID (Database for Annotation, Visualization and Integrated Discovery) [33] using Gene Ontology (GO), KEGG and Reactome databases. Enrichment analysis for GeneGo functional ontologies (Pathway Maps, Process Networks and GO processes), and analysis using Interactome and Network building tools was performed in MetaCore $^{\mathrm{Tm}}$ (GeneGo, St. Joseph, MI) [55]. The MetaCore default setting of false discovery rate $($ FDR $)<0.05$ was used as threshold for significance in enrichment analysis.

\section{Gene Set Enrichment Analysis (GSEA)}

Expression data for Atlantic cod genes that could be mapped to putative human orthologs (BLASTX with human UniProtKB/Swiss-Prot database, E-value $<10^{-6}$ ) (8.2 k genes in total) were used for gene set enrichment analysis (GSEA) [32]. Gene symbols for the $8.2 \mathrm{k}$ unique genes were used as identifiers to perform GSEA. GSEA software and gene sets in the Molecular Signatures Database (MSigDB) [56] at Broad Institute (http://www. broadinstitute.org/gsea/index.jsp) were used. GSEA was performed with the control, 0.5, 2 and $8 \mathrm{mg} / \mathrm{kg}$ BW PCB 153 doses as continuous class labels with 1000 permutations of phenotypes. The absolute Pearson correlation metric was selected for ranking genes in descending order. The option for absolute correlation was chosen for ranking since it places the most differentially regulated (both up-regulated and down regulated) genes at the top of the ranked order and the least changing genes at the bottom. The curated Reactome, GenMAPP and KEGG gene sets in MSigDB were used. Gene sets enriched with FDR < 0.25 were considered significant as recommended [32].

\section{Quantitative real-time PCR (qPCR)}

For each sample, cDNA synthesis was performed from total RNA $(1.0 \mu \mathrm{g})$ using reverse- SuperScript III FirstStrand Synthesis System for RT-PCR in $20 \mu \mathrm{L}$ reaction as described in the manufacturer's protocols (Invitrogen). qPCR assay and analysis was performed as described before [28]. Results are presented as means \pm standard deviations. For confirmation of microarray results by qPCR, statistical analysis was performed on $\log _{2}$-transformed fold changes of expression (treated/ control) using one-tailed Student's t-test, and p $<0.05$ was considered significant. For the qPCR assay of larger sample size, two samples (one from control and one from $2 \mathrm{mg} / \mathrm{kg}$ BW PCB 153 treated group) were found 
to be significant outliers $(p<0.05)$ using Grubb's test in GraphPad outlier calculator (http://graphpad.com/quickcalcs/Grubbs1.cfm) and excluded from the analysis. For the GPCR assay of larger sample size, statistical analysis of log2-transformed fold-changes was performed using one-way ANOVA and Dunnett's multiple comparison post-test (GraphPad Prism Software, La Jolla, CA, USA).

\section{Additional files}

Additional file 1: Table S1. The file contains 165 genes differentially regulated by PCB 153, which were used in pathway analysis.

Additional file 2: Figure S1. Comparison of fold changes of expression by microarray and qPCR; Figure S2. Enriched liver-specific ontologies; Table S2. A full list of significantly enriched GeneGo pathway maps; Table S3. Significantly enriched GO Processes; Table S4. significantly enriched top 20 GeneGo process networks; Table S5. significantly enriched Transcription Factors.

Additional file 3: Is an excel document with a full list of significantly enriched Reactome gene sets.

\section{Abbreviations}

PCB: Polychlorinated biphenyl; POP: Persistent organic pollutant; BW: Body weight; AhR: Aryl hydrocarbon receptor; SXR: Steroid and xenobiotic receptor; PXR: Pregnane $X$ receptor; CAR: Constitutive androstane receptor; DAVID: Database for Annotation, Visualization and Integrated Discovery; SAM: Significance Analysis of Microarrays; FDR: False Discovery Rate; qPCR: Quantitative real-time polymerase chain reaction; GSEA: Gene Set Enrichment Analysis; FABP: Fatty acid binding protein; SREBP: Sterol regulatory element-binding protein; PPARG: Peroxisome proliferator-activated receptor gamma; PCNA: Proliferating Cell Nuclear Antigen; SCAP: SREBP chaperone; GO: Gene Ontology; BP: Biological process; ACLY: ATP citrate lyase; ACACA: Acetyl-CoA carboxylase (ACC); ACSA: Acetyl-CoA synthetase; FASN: Fatty acid synthase; SCD5: Stearoyl-CoA desaturase 5; E2F1: EGR1, Early growth response 1; MAPK: Mitogen-activated protein kinase; KEGG: Kyoto Encyclopedia of Genes and Genomes; GenMAPP: Gene Map Annotator and Pathway Profiler; MCM5: Minichromosome Maintenance Complex Component 5; ES: Enrichment score; NES: Normalized ES; Nom p-val: Nominal p-value.

\section{Competing interests}

The authors declare that they have no competing interests.

\section{Authors' contributions}

FY coordinated array design and data acquisition, performed array data analysis and drafted the manuscript. OAK coordinated the project, participated in data analysis and reviewed the manuscript. ME participated in array data validation experiments, and reviewed the manuscript. CH participated in microarray experiment design, data analysis and reviewed the manuscript. AG conceived of the study, participated in its design, coordinated the study, and reviewed the manuscript. All authors read and approved the final manuscript.

\section{Acknowledgements}

The authors thank the Genofisk Consortium and the Cod Genome Sequencing Project Team for sharing data in advance of the public release of the cod genome data. The project (iCOD) is funded by the Norwegian Research Council (project 192441/130).

\section{Author details}

${ }^{1}$ Department of Molecular Biology, University of Bergen, Bergen, Norway. ${ }^{2}$ Department of Biology, University of Bergen, Bergen, Norway. ${ }^{3}$ Diabetes and Nutritional Sciences Division, King's College London, London, UK.

Received: 1 April 2014 Accepted: 11 June 2014

Published: 17 June 2014

\section{References}

1. Safe SH: Polychlorinated biphenyls (PCBs): Environmental impact, biochemical and toxic responses, and implications for risk assessment. Crit Rev Toxicol 1994, 24(2):87-149.

2. Jonsson A, Gustafsson O, Axelman J, Sundberg H: Global accounting of PCBs in the continental shelf sediments. Environ Sci Technol 2003, 37(2):245-255

3. Judd N, Griffith WC, Faustman EM: Contribution of PCB exposure from fish consumption to total dioxin-like dietary exposure. Regul Toxicol Pharmacol 2004, 40(2):125-135.

4. McFarland VA, Clarke JU: Environmental occurrence, abundance, and potential toxicity of polychlorinated biphenyl congeners: considerations for a congener-specific analysis. Environ Health Perspect 1989, 81:225-239.

5. Al-Salman F, Plant N: Non-coplanar polychlorinated biphenyls (PCBs) are direct agonists for the human pregnane- $X$ receptor and constitutive androstane receptor, and activate target gene expression in a tissue-specific manner. Toxicol Appl Pharmacol 2012, 263(1):7-13.

6. Hurst $\mathrm{CH}$, Waxman DJ: Interactions of Endocrine-active environmental chemicals with the nuclear receptor PXR. Toxicol Environ Chem 2005, 87(1-4):299-311. 287

7. Hedge JM, DeVito MJ, Crofton KM: In vivo acute exposure to polychlorinated biphenyls: effects on free and total thyroxine in rats. Int J Toxicol 2009, 28(5):382-391.

8. Lyche JL, Oskam IC, Skåe JU, Reksen O, Sweeney T, Dahl E, Farstad W, Ropstad E: Effects of gestational and lactational exposure to low doses of PCBs 126 and 153 on anterior pituitary and gonadal hormones and on puberty in female goats. Reprod Toxicol 2004, 19(1):87-95.

9. Berg K, Puntervoll P, Klungsøyr J, Goksøyr A: Brain proteome alterations of Atlantic cod (Gadus morhua) exposed to PCB 153. Aquat Toxicol 2011, 105(3-4):206-217.

10. Dean CE, Benjamin SA, Chubb LS, Tessari JD, Keefe TJ: Nonadditive hepatic tumor promoting effects by a mixture of two structurally different polychlorinated biphenyls in female rat livers. Toxicol Sci 2002, 66(1):54-61.

11. Alonso-Magdalena P, Quesada I, Nadal A: Endocrine disruptors in the etiology of type 2 diabetes mellitus. Nat Rev Endocrino/ 2011, 7(6):346-353.

12. Casals-Casas C, Desvergne B: Endocrine disruptors: from endocrine to metabolic disruption. Annual Rev Physiol 2011, 73:135-162.

13. Grün F, Blumberg B: Endocrine disrupters as obesogens. Mol Cell Endocrinol 2009, 304(1-2):19-29.

14. Lee D-H, Lee I-K, Song K, Steffes M, Toscano W, Baker BA, Jacobs DR Jr: A strong dose-response relation between serum concentrations of persistent organic pollutants and diabetes - results from the National Health and Examination Survey 1999-2002. Diabetes Care 2006, 29(7):1638-1644.

15. Ruzzin J, Lee D-H, Carpenter DO, Jacobs DR Jr: Reconsidering metabolic diseases: the impacts of persistent organic pollutants. Atherosclerosis 2012, 224(1):1-3.

16. Ruzzin J, Petersen R, Meugnier E, Madsen L, Lock EJ, Lillefosse H, Ma T, Pesenti S, Sonne SB, Marstrand TT, Malde MK, Du ZY, Chavey C, Fajas L, Lundebye AK, Brand CL, Vidal H, Kristiansen K, Frøyland L: Persistent organic pollutant exposure leads to insulin resistance syndrome. Environ Health Perspect 2010, 118(4):465-471.

17. Thayer KA, Heindel JJ, Bucher JR, Gallo MA: Role of environmental chemicals in diabetes and obesity: a national toxicology program workshop review. Environ Health Perspect 2012, 120(6):779-789.

18. Wahlang B, Falkner KC, Gregory B, Ansert D, Young D, Conklin DJ, Bhatnagar A, McClain CJ, Cave M: Polychlorinated biphenyl 153 is a diet-dependent obesogen that worsens nonalcoholic fatty liver disease in male C57BL6/J mice. J Nutr Biochem 2013, 24(9):1587-1595.

19. Hu P, Chen X, Whitener RJ, Boder ET, Jones JO, Porollo A, Chen J, Zhao L: Effects of parabens on adipocyte differentiation. Toxicol Sci 2013, 131(1):56-70.

20. Taxvig C, Dreisig K, Boberg J, Nellemann C, Schelde AB, Pedersen D, Boergesen M, Mandrup S, Vinggaard AM: Differential effects of environmental chemicals and food contaminants on adipogenesis, biomarker release and PPAR gamma activation. Mol Cell Endocrinol 2012, 361(1-2):106-115.

21. Oka T, Nishimura $Y$, Zang L, Hirano M, Shimada $Y$, Wang Z, Umemoto N, Kuroyanagi J, Nishimura N, Tanaka T: Diet-induced obesity in zebrafish shares common pathophysiological pathways with mammalian obesity. BMC Physiol 2010, 10(1):21.

22. Seth A, Stemple DL, Barroso I: The emerging use of zebrafish to model metabolic disease. Dis Model Mech 2013, 6(5):1080-1088. 
23. Tingaud-Sequeira A, Ouadah N, Babin PJ: Zebrafish obesogenic test: a tool for screening molecules that target adiposity. J Lipid Res 2011, 52(9):1765-1772.

24. Eide M, Karlsen OA, Kryvi H, Olsvik PA, Goksøyr A: Precision-cut liver slices of Atlantic cod (Gadus morhua): an in vitro system for studying the effects of environmental contaminants. Aquat Toxicol 2013, http://dx.doi. org/10.1016/j.aquatox.2013.10.027.

25. Karlsen OA, Bjørneklett S, Berg K, Brattås M, Bohne-Kjersem A, Grøsvik BE, Goksøyr A: Integrative Environmental Genomics of Cod (Gadus morhua): the Proteomics Approach. J Toxicol Environ Health-Part a-Curr Issues 2011, 74(7-9):494-507.

26. Kidd K, Holth TF, Thorsen A, Olsvik PA, Hylland K: Long-term exposure of Atlantic cod (Gadus morhua) to components of produced water: condition, gonad maturation, and gene expression. Can J Fish Aquat Sci 2010, 67(10):1685-1698.

27. Star B, Nederbragt AJ, Jentoft S, Grimholt U, Malmstrom M, Gregers TF, Rounge TB, Paulsen J, Solbakken MH, Sharma A, Wetten OF, Lanzén A, Winer R, Knight J, Vogel JH, Aken B, Andersen O, Lagesen K, Tooming-Klunderud A, Edvardsen RB, Tina KG, Espelund M, Nepal C, Previti C, Karlsen BO, Moum T, Skage M, Berg PR, Gjøen T, Kuhl H: The genome sequence of Atlantic cod reveals a unique immune system. Nature 2011, 477(7363):207-210.

28. Yadetie F, Karlsen OA, Lanzen A, Berg K, Olsvik P, Hogstrand C, Goksøyr A: Global transcriptome analysis of Atlantic cod (Gadus morhua) liver after in vivo methylmercury exposure suggests effects on energy metabolism pathways. Aquat Toxicol 2013, 126:314-325

29. Ankley GT, Bennett RS, Erickson RJ, Hoff DJ, Hornung MW, Johnson RD, Mount DR, Nichols JW, Russom CL, Schmieder PK, Serrrano JA, Tietge JE, Villeneuve DL: Adverse outcome pathways: a conceptual framework to support ecotoxicology research and risk assessment. Environ Toxicol Chem 2010, 29(3):730-741

30. Martyniuk CJ, Griffitt RJ, Denslow ND: Omics in aquatic toxicology: not just another microarray. Environ Toxicol Chem 2011, 30((1552-8618 (Electronic))):263-264.

31. Van Aggelen G, Ankley GT, Baldwin WS, Bearden DW, Benson WH, Chipman JK, Collette TW, Craft JA, Denslow ND, Embry MR, Falciani F, George SG, Helbing CC, Hoekstra PF, Iguchi T, Kagami Y, Katsiadaki I, Kille P, Liu L, Lord PG, Mclntyre T, O'Neill A, Osachoff H, Perkins EJ, Santos EM, Skirrow RC, Snape JR, Tyler CR, Versteeg D, Viant MR, Volz DC, Williams TD, Yu L: Integrating omic technologies into aquatic ecological risk assessment and environmental monitoring: hurdles, achievements, and future outlook. Environ Health Perspect 2010, 118(1):1-5.

32. Subramanian A, Tamayo P, Mootha VK, Mukherjee S, Ebert BL, Gillette MA, Paulovich A, Pomeroy SL, Golub TR, Lander ES, Mesirov JP: Gene set enrichment analysis: a knowledge-based approach for interpreting genome-wide expression profiles. Proc Natl Acad Sci U S A 2005, 102 (43):15545-15550.

33. Dennis G, Sherman BT, Hosack DA, Yang J, Gao W, Lane HC, Lempicki RA: DAVID: Database for annotation, visualization, and integrated discovery. Genome Biol 2003, 4:3.

34. Shimano H: Sterol regulatory element-binding proteins (SREBPs): transcriptional regulators of lipid synthetic genes. Prog Lipid Res 2001, 40(6):439-452.

35. Roth A, Looser R, Kaufmann M, Blättler SM, Rencurel F, Huang W, Moore DD, Meyer UA: Regulatory cross-talk between drug metabolism and lipid homeostasis: constitutive androstane receptor and pregnane $\mathrm{X}$ receptor increase Insig-1 expression. Mol Pharmacol 2008, 73(4):1282-1289.

36. Meruvu S, Hugendubler L, Mueller E: Regulation of adipocyte differentiation by the zinc finger protein ZNF638. J Biol Chem 2011, 286(30):26516-26523.

37. DeLigio JT, Zorio DA: Early growth response 1 (EGR1): a gene with as many names as biological functions. Cancer Biol Ther 2009, 8(20):1889-1892.

38. Thiel G, Cibelli G: Regulation of life and death by the zinc finger transcription factor Egr-1. J Cell Physiol 2002, 193(3):287-292.

39. Gokey NG, Lopez-Anido C, Gillian-Daniel A, Svaren J: Early growth response 1 (Egr1) regulates cholesterol biosynthetic gene expression. J Biol Chem 2011, 286(1083-351× (Electronic)):29501-29510.

40. Mootha VK, Lindgren CM, Eriksson KF, Subramanian A, Sihag S, Lehar J, Puigserver P, Carlsson E, Ridderstrale M, Laurila E, Houstis N, Daly MJ, Patterson N, Mesirov JP, Golub TR, Tamayo P, Spiegelman B, Lander ES, Hirschhorn JN, Altshuler D, Groop LC: PGC-1 alpha-responsive genes involved in oxidative phosphorylation are coordinately downregulated in human diabetes. Nat Genet 2003, 34(3):267-273.
41. Roberts R, Hodson L, Dennis AL, Neville MJ, Humphreys SM, Harnden KE, Micklem KJ, Frayn KN: Markers of de novo lipogenesis in adipose tissue: associations with small adipocytes and insulin sensitivity in humans. Diabetologia 2009, 52(5):882-890

42. Wakil SJ, Stoops JK, Joshi VC: Fatty acid synthesis and its regulation. Annu Rev Biochem 1983, 52:537-579.

43. Tang QQ, Lane MD: Adipogenesis: From Stem Cell to Adipocyte. In Annual Review of Biochemistry, Vol 81. vol. 81st edition. Edited by Kornberg RD. Palo Alto: Annual Reviews; 2012:715-736.

44. Marmugi A, Ducheix S, Lasserre F, Polizzi A, Paris A, Priymenko N, BertrandMichel J, Pineau T, Guillou H, Martin PGP, Mselli-Lakhal L: Low doses of bisphenol a induce gene expression related to lipid synthesis and trigger triglyceride accumulation in adult mouse liver. Hepatology 2012, 55(2):395-407

45. Flynn EJ III, Trent CM, Rawls JF: Ontogeny and nutritional control of adipogenesis in zebrafish (Danio rerio). J Lipid Res 2009, 50(8):1641-1652.

46. Schlegel A, Stainier DYR: Lessons from "lower" organisms: What worms, flies, and zebrafish can teach us about human energy metabolism. Plos Genetics 2007, 3(11):2037-2048.

47. Asker N, Kristiansson E, Albertsson E, Larsson D, Förlin L: Hepatic transcriptome profiling indicates differential mRNA expression of apoptosis and immune related genes in eelpout (Zoarces viviparuscaught at Göteborg harbor, Sweden. Aquat Toxicol 2013, 130:58-67.

48. Bohne-Kjersem A, Skadsheim A, Goksøyr A, Grøsvik BE: Candidate biomarker discovery in plasma of juvenile cod (Gadus morhua) exposed to crude North Sea oil, alkyl phenols and polycyclic aromatic hydrocarbons (PAHs). Mar Environ Res 2009, 68(5):268-277.

49. Leaver MJ, Diab A, Boukouvala E, Williams TD, Chipman JK, Moffat CF, Robinson CD, George SG: Hepatic gene expression in flounder chronically exposed to multiply polluted estuarine sediment: absence of classical exposure 'biomarker'signals and induction of inflammatory, innate immune and apoptotic pathways. Aquat Toxicol 2010, 96(3):234-245.

50. Lie KK, Lanzen A, Breilid H, Olsvik PA: Gene expression profiling in Atlantic cod (Gadus morhua L.) from two contaminated sites using a custommade cDNA microarray. Environ Toxicol Chem 2009, 28(8):1711-1721.

51. Sagerup K, Larsen HJS, Skaare JU, Johansen GM, Gabrielsen GW: The toxic effects of multiple persistent organic pollutant exposures on the post-hatch immunity maturation of glaucous gulls. J Toxic Environ Health A 2009, 72(14):870-883.

52. Tusher VG, Tibshirani R, Chu G: Significance analysis of microarrays applied to the ionizing radiation response. Proc Natl Acad Sci U S A 2001, 98(9):5116-5121.

53. Dysvik B, Jonassen I: J-Express: exploring gene expression data using Java. Bioinformatics 2001, 17(4):369-370

54. Eisen MB, Spellman PT, Brown PO, Botstein D: Cluster analysis and display of genome-wide expression patterns. Proc Natl Acad Sci 1998, 95 (25):14863-14868.

55. Ekins S, Bugrim A, Brovold L, Kirillov E, Nikolsky Y, Rakhmatulin E, Sorokina S, Ryabov A, Serebryiskaya T, Melnikov A, Metz J, Nikolskaya T: Algorithms for network analysis in systems-ADME/Tox using the MetaCore and MetaDrug platforms. Xenobiotica 2006, 36(10-11):877-901.

56. Liberzon A, Subramanian A, Pinchback R, Thorvaldsdottir H, Tamayo P. Mesirov JP: Molecular signatures database (MSigDB) 3.0. Bioinformatics 2011, 27(12):1739-1740.

doi:10.1186/1471-2164-15-481

Cite this article as: Yadetie et al:: Liver transcriptome analysis of Atlantic cod (Gadus morhua) exposed to PCB 153 indicates effects on cell cycle regulation and lipid metabolism. BMC Genomics 2014 15:481. 